\title{
Early imaging of a macular hole following vitrectomy with primary silicone oil tamponade
}

This article was published in the following Dove Press journal:

Clinical Ophthalmology

I4 November 201।

Number of times this article has been viewed

\section{Niladri Saha \\ Stewart Lake \\ Bob Z Wang}

Department of Ophthalmology, Flinders Medical Centre and Flinders University, Bedford Park, South Australia, Australia
Correspondence: Bob Z Wang Department of Ophthalmology, Flinders Medical Centre and Flinders University, Flinders Drive, Bedford Park, South Australia 5042, Australia

Tel +6I 8820455 I I

Fax +6I 882045450

E-mail bobzwang@gmail.com
Background: To describe the morphology of a macular hole in the early postoperative period following vitrectomy with primary silicone oil tamponade.

Methods: A case report with optical coherence tomography (OCT) scans prior to surgery, at 20 minutes postoperatively and then at 17 hours postoperatively.

Results: OCT images of a 73-year-old woman with a stage 3 macular hole were obtained. At 20 minutes postoperatively, there was a reduction in intraretinal cysts and a reduction in macular hole size with elevated-open configuration. At 17 hours postoperatively, complete macular hole closure was noted.

Conclusion: OCT Images of a macular hole in the early postoperative period have been successfully obtained. Macular holes can close within 24 hours postoperatively and show morphological changes that may be predictive of closure within 20 minutes postoperatively.

Keywords: early imaging, macular hole, vitrectomy

\section{Introduction}

Macular hole closure is generally achieved within 3 days following macular hole surgery. If hole closure is not achieved within this period, the hole is unlikely to close without further surgical intervention. ${ }^{1}$ However, it is unclear how macular holes behave within the first 24 hours postoperatively, with no published reports of findings during this time frame. We present a case where imaging with optical coherence tomography (OCT) was achieved in the early postoperative period and describe the morphological changes following macular hole surgery.

\section{Case report}

A 73-year-old female of Aboriginal origin from a sparsely populated area of Australia had travelled 4 hours by air to receive specialist assessment and treatment of her visual complaint. She presented with an 8-week history of decreased vision in her left eye. Best corrected visual acuity in the left eye was 20/100 and OCT imaging revealed a stage 3 macular hole (Figure 1).

Following discussion with the patient, and taking into consideration her desire to fly home as soon as possible, the decision was made to undertake macular hole surgery with silicone oil tamponade. Surgery was uncomplicated using a contact lens viewing system and consisted of transconjunctival sutureless 25-gauge vitrectomy with trypan blueassisted internal limiting membrane peel and 1000 centistokes silicone oil tamponade.

OCT images were taken 20 minutes following surgery. The images showed a persistent but reduced hole size, a decrease in intraretinal cysts, and the absence of subretinal 


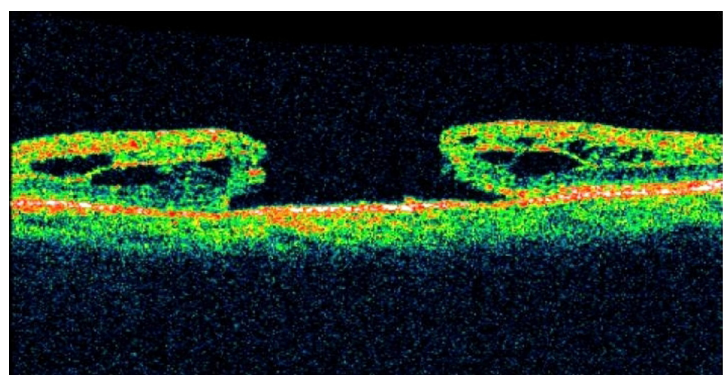

Figure I Preoperative - stage 3 macular hole.

fluid (Figure 2). The configuration was elevated-open in all sections. Further OCT images were taken at 17 hours and showed hole closure in all image sections with restoration of relatively normal foveal contour (Figure 3).

\section{Discussion}

Current treatment of macular holes involves pars plana vitrectomy, intraocular gas tamponade, and face-down posturing. However, our patient preferred to fly home following surgery. Based on this decision and appropriate counseling, the patient was offered an oil tamponade rather than a gas tamponade as the decreased atmospheric pressure during air travel increases the risk of gas expansion, and ultimately increases intraocular pressure. Using primary oil tamponade in macular hole surgery is not a novel technique, and has often been used in those patients who cannot lie face down. ${ }^{2}$ It also has the advantage of allowing fundus examination and OCT imaging in the early postoperative period with commercially available systems.

Vertical OCT scanning with the patient in a prone position has been used previously to image postoperative macular

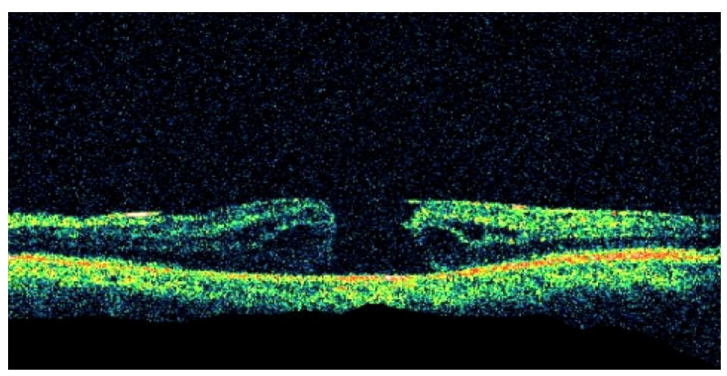

Figure 220 minutes postoperative - reduction in hole size (elevated-open configuration) with decrease in intraretinal cysts and absence of subretinal fluid.

Clinical Ophthalmology

\section{Publish your work in this journal}

Clinical Ophthalmology is an international, peer-reviewed journal covering all subspecialties within ophthalmology. Key topics include: Optometry; Visual science; Pharmacology and drug therapy in eye diseases; Basic Sciences; Primary and Secondary eye care; Patient Safety and Quality of Care Improvements. This journal is indexed on

Submit your manuscript here: http://www.dovepress.com/clinical-ophthalmology-journal

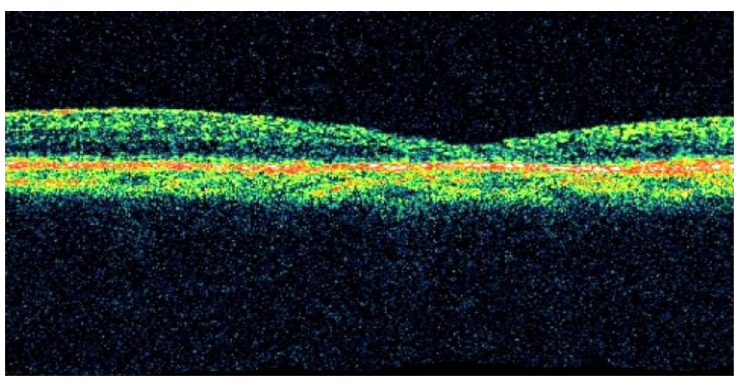

Figure 317 hours postoperative - closed hole with restoration of foveal contour.

holes in gas-filled eyes. ${ }^{1}$ Such a system, however, is not commercially available and to the best of our knowledge, we are not aware of early images being available.

This case displayed rapid macular hole closure. Using OCT, it was possible to observe a reduction in intraretinal cysts and an elevated-open configuration within 20 minutes postoperatively. This reduction in retinal cysts and elevatedopen configuration has been proposed as an effective predictor of macular hole closure. ${ }^{3}$ Complete macular hole closure was achieved at some point between 20 minutes and 17 hours following surgery.

In conclusion, we have successfully imaged a macular hole in the early postoperative period. Our case highlights that macular holes can close well within 24 hours after surgery and show morphological changes which may be predictive of closure within 20 minutes.

\section{Disclosures}

The authors report no conflicts of interest in this work. The paper was presented at the Royal Australian and New Zealand College of Ophthalmologists scientific conference in Adelaide, Australia in November, 2010.

\section{References}

1. Eckardt C, Eckert T, Eckardt U, Porkert U, Gesser C. Macular hole surgery with air tamponade and optical coherence tomography-based duration of face-down positioning. Retina. 2008;28(8):1087-1096.

2. Goldbaum MH, McCuen BW, Hanneken AM, Burgess SK, Chen HH. Silicone oil tamponade to seal macular holes without position restrictions. Ophthalmology. 1998;105(11):2140-2147; discussion 2147-2148.

3 . Hotta K. Early postoperative macular features determined by optical coherence tomography after idiopathic macular hole surgery with silicone oil tamponade. Ophthalmic Surg Lasers Imaging. 2005;36(5):426-431.

\section{Dovepress}

PubMed Central and CAS, and is the official journal of The Society of Clinical Ophthalmology (SCO). The manuscript management system is completely online and includes a very quick and fair peer-review system, which is all easy to use. Visit http://www.dovepress.com/ testimonials.php to read real quotes from published authors. 